\title{
COOPERATIVISMO E ESTRATÉGIAS COMPETITIVAS: UM ESTUDO DE \\ MULTICASOS NAS COOPERATIVAS DE CRÉDITO MÚTUO E DE \\ CRÉDITO RURAL NAS CIDADES DE MINAS GERAIS
}

\author{
Jussara Maria Silva Rodrigues Oliveira \\ Doutora em Administração / Professora do UNIFOR-MG \\ Virgínia Dias Lages \\ Graduanda do curso de Engenharia Ambiental do UNIFOR-MG \\ Bolsista da FAPEMIG / virginiadias@ymail.com \\ Marcela Pecze de Morais \\ Graduanda do Curso de Engenharia Ambiental do UNIFOR-MG
}

\begin{abstract}
RESUMO
O cooperativismo é um sistema econômico que pode promover o desenvolvimento sócio-econômico e ambiental. O objetivo da pesquisa foi estudar as estratégias competitivas adotadas por onze cooperativas de crédito mútuo e rural, pertencentes aos municípios do Estado de Minas Gerais. O procedimento metodológico utilizado foi pesquisa qualitativa, descritiva e de multicasos. A pesquisa é um estudo de multicasos, por se tratar de onze cooperativas, caracterizadas pelo maior foco na compreensão e na comparação qualitativa dos fenômenos. Os instrumentos de coleta de dados foram o questionário semiestruturado, roteiro de entrevista e observação-participante. Deste modo, as cooperativas de crédito rural pertencentes as cidades de Bom Despacho, Bambuí, Campo Belo e Nanuque atuam na formação de programas educacionais, conscientização ambiental e menores taxas de juros. As cooperativas de crédito mútuo situadas nas cidades de Formiga, Viçosa, Ouro Branco, Campos Gerais, Sabinópolis e Alpinópolis têm cumprido o seu papel, priorizando ações associativas, menores taxas de serviços, visando o desenvolvimento regional. Tanto as cooperativas de crédito rural quanto as cooperativas de crédito mútuo visam os desenvolvimentos sócio-econômico e ambiental na região de atuação.
\end{abstract}

Palavras-chaves: Estratégias. Cooperativismo. Desenvolvimento

\section{COOPERATIVE AND COMPETITIVE STRATEGIES: A STUDY IN MULTICASE CREDIT}

UNIONS AND RURAL CREDIT IN THE CITIES OF MINAS GERAIS

\begin{abstract}
The cooperative is an economic system that can promote socio-economic and environmental. The purpose of this research was to study the competitive strategies of eleven credit unions and rural areas belonging to municipalities of Minas Gerais. The approach used was qualitative, descriptive and multicase. The research is a study of multi for treating eleven cooperatives, characterized by greater focus on understanding and qualitative comparison of the phenomena. The instruments of data collection was semistructured interviews and participant observation. Thus the rural credit cooperatives in the cities of Bom Despacho, Bambuí, Nanuque and Campo Belo operates in the formation of educational programs, environmental awareness, and lower interest rates and credit unions in the cities of Formiga, Viçosa, Ouro Branco, Campos Gerais, Sabinópolis and Alpinópolis have fulfilled their role, emphasizing cooperative actions, lower rates of services, to regional development. Both the rural credit cooperatives as the credit unions seeking to develop socio-economic and environmental performance in their region.
\end{abstract}


Keywords: Strategies. Cooperatives. Development

\section{INTRODUÇÃO}

O cooperativismo tem sido uma forma de movimento social consagrada na maioria dos países do mundo. Esse sistema é um importante instrumento de distribuição de renda, além de promover ações, satisfazendo um grupo de pessoas com interesses comuns, voltado, principalmente, para atender suas necessidades econômicas, culturais, sociais e ambientais.

Os conceitos de desenvolvimento sustentável, sustentabilidade e cooperativismo possuem fortes laços de interligação, os quais permitem a identificação de diversas características comuns em termos de objetivos e interações. Estas interações são constituídas e mantidas na constante busca de geração de valor, a partir da rede de relações sociais e do atingimento de metas que permitam um crescimento conjunto justo, sustentável e equilibrado. Nestes conceitos podem ser identificados elementos que demonstram uma preocupação com o estabelecimento de relações de equilíbrio entre agentes que interagem economicamente e socialmente em um mesmo ambiente. Há também uma forte preocupação no sentido de fazer com que os objetivos organizacionais se sobreponham aos objetivos individuais.

No Brasil, pode-se perceber um renascimento do cooperativismo de crédito mútuo, tanto no nível urbano como também voltado para o crédito rural. Atualmente, mesmo com a expansão das cooperativas de crédito mútuo e rural, faltam estudos ou propostas que avaliem, de forma sistemática, o dinamismo existente e as estratégias cooperativas adotadas.

Segundo Shardong (2002), a cooperativa de crédito, como espécie do gênero "cooperativa", objetiva promover a captação de recursos financeiros para financiar as atividades econômicas dos cooperados, a administração das suas poupanças e a prestação dos serviços de natureza bancária por eles demandada.

A relevância do estudo sobre cooperativismo parte de uma premissa, instrumento de promoção da cooperação e da igualdade dos membros, que deve ser colocada sempre em evidência. De fato, essa premissa atravessou séculos de embates e, com o passar dos tempos, se fortalece: a igualdade das sociedades cooperativas. (SOUZA, 2008).

O desenvolvimento no setor de cooperativismo de crédito ocorre num momento de abertura da economia, com consequente estabelecimento de novas condições para a competitividade de mercado. A ampliação do estudo de dinamismo do cooperativismo de crédito configura-se pela instituição de forças para reorientar estratégias. Os dirigentes e associados estão se deparando com a necessidade de fazer reconhecer, com maior capilaridade, o sistema como um todo. (SHARDONG, 2003).

Abre-se um questionamento sobre a situação do cooperativismo de crédito mútuo e rural no Brasil, particularmente em Minas Gerais. Nessa perspectiva, ocorre um duplo confronto entre ambientes percebidos e reais (SMIRCH e STUBART, 1985). Com isto, os dirigentes não estão sincronizados, ao mesmo tempo, com as duas vertentes: o contexto organizacional e o econômico. Diante disto, pode-se afir- 
mar que a gestão estratégica não está se realizando nas suas reais dimensões, tornando-se claro que há um problema de percepção por parte dos dirigentes do aspecto associativo, inerente às organizações cooperativas.

Segundo Coté e Vézima (1994) e Portilho (2005), de maneira geral, as cooperativas apresentam diferentes estratégias ao longo do tempo, entre a estrutura organizacional e sua estrutura democrática. Nessas diferentes situações, uma cooperativa se encontra em face de desafios. Essas transformações representam um elemento importante de integração, na medida em que se agrega um conjunto de características que articulam temas como qualidade, ética, defesa do meio ambiente e cidadania. Reconhece-se a necessidade de enfatizar práticas coletivas como norteadoras de um processo que, embora englobe os consumidores individuais, prioriza ações na sua dimensão associativa.

Os associados contribuem equitativamente e controlam democraticamente o capital de sua cooperativa. Ao menos parte desse capital é, em sua maioria, de propriedade comum da cooperativa. Os associados, geralmente, recebem benefícios limitados pelo capital subscrito, quando houver, como condição de associação. As cooperativas fornecem educação e treinamento a seus sócios, aos representantes elei- tos, aos administradores e empregados, para que eles possam contribuir efetivamente, com o desenvolvimento de sua cooperativa. (SOUZA, 2008).

Nesse sentido, a presente pesquisa tem como objetivo estudar as estratégias competitivas de 11 (onze) cooperativas de crédito mútuo e de crédito rural nos municípios do Estado de Minas Gerais, por meio do desenvolvimento econômico, social e ambiental. Sendo assim foram estudadas as cooperativas de crédito rural nas cidades de Bom Despacho, Bambuí, Campo Belo e Nanuque. E as cooperativas de crédito mútuo nas cidades de Formiga, Viçosa, Ouro Branco, Campos Gerais, Sabinópolis e Alpinópolis.

\section{MATERIAL E MÉTODOS}

Minas Gerais é uma das 27 unidades federativas do Brasil, sendo a quarta maior em extensão territorial, que é de $586.528 \mathrm{~km}^{2}$, equivalente à da França. Possui o terceiro maior Produto Interno Bruto (PIB) do Brasil, superado apenas pelos estados de São Paulo e Rio de Janeiro, embora em um importante indicador de capacidade econômica, a arrecadação de ICMS, Minas tenha superado o Rio de Janeiro na classificação nacional. (IBGE, 2010).

A pesquisa foi realizada em 11(onze) cooperativas de diferentes regiões do Estado de Minas Gerais. Foram estudadas 2 (duas) cooperativas de crédito mútuo, uma instalada há 17 anos, e outra há 15 anos atuando no mercado, ambas na cidade de Formiga. O município de Formiga está situado na região Centro-Oeste de Minas Gerais, segundo a divisão geográfica do estado, possuindo uma área de 1.501,02 $\mathrm{km}^{2}$. A cooperativa na cidade de Bom Despacho, instalada há 23 anos no mercado. O município de Bom Despacho está situado na região do Alto São Francisco, no Centro-Oeste de Minas Gerais, possuindo 
uma área de $1218,12 \mathrm{~km}^{2}$.

A cooperativa de crédito rural na cidade de Bambuí está há 18 anos no mercado. O município de Bambuí está situado também no Centro-Oeste do estado com uma área de 1453,99 km². O município de Campo Belo está situado na microrregião do Centro-Oeste mineiro, possuindo uma área de $51.375 \mathrm{~km}^{2}$, com uma cooperativa de crédito rural instalada há 16 anos no município. A cidade de Nanuque é pólo sócio-econômico e cultural da microrregião Vale do Mucuri (região Nordeste), com uma área de $1.542,97 \mathrm{~km}^{2}$. A cooperativa atua há 16 anos no mercado.

Em se tratando das cooperativas de crédito mútuo, a cooperativa do município de Viçosa localiza-se na Zona da Mata mineira, com uma área de 300,15 km², e atua no mercado há 11 anos. O município de Ouro Branco está situado na região Central do Estado, possuindo uma área de $258,79 \mathrm{~km}^{2}$, abrangendo a cooperativa de crédito mútuo instalada há 28 anos no mercado.

A cidade de Campos Gerais está situada no sul de Minas, com uma área de 770,3 km², na Bacia Rio Grande, abrangendo a cooperativa de crédito rural instalada há 16 anos no mercado. O município de Sabinópolis está localizado na Bacia do Rio Doce, com uma área de 919,49 km², possuindo a cooperativa de crédito mútuo atuando, há 12 anos, no mercado da região. A outra cooperativa de crédito mútuo encontra-se na cidade de Alpinópolis, há 21 anos no mercado. A cidade de Alpinópolis localiza-se no sul do estado e com uma área de $456,47 \mathrm{~km}^{2}$. Seu nome deve-se às elevações da Serra da Ventania, que lembram os Alpes. (ALMG, 2010).

A pesquisa classifica-se como pesquisa descritiva e qualitativa. Para Gil (1999), os estudos descritivos exigem uma série de informações sobre o que se deseja pesquisar, descrevendo, com exatidão, os fatos e fenômenos de determinada realidade. No campo das Ciências Sociais, o termo pesquisa qualitativa assumiu diferentes significados, como o de compreender um conjunto de diversas técnicas interpretativas que objetiva descrever e decodificar os componentes de um sistema complexo de significados. Pretende traduzir e expressar o sentido dos fenômenos do mundo social e trata-se de reduzir a distância entre o pesquisador e o pesquisado, entre a teoria e os dados, entre o contexto e a ação (MAANEN,1979, p.520). O principal fundamento da pesquisa qualitativa é a imersão do pesquisador no contexto e a perspectiva interpretativa de condução da pesquisa. (KAPLAN; DUCHON, 1988, p. 580).

A pesquisa é um estudo de multicasos (YIN, 2001), por se tratar de onze cooperativas de crédito, caracterizados pelo maior foco na compreensão e na comparação qualitativa dos fenômenos. O estudo multicasos proporciona uma maior abrangência dos resultados, não se limitando às informações de uma só organização. De acordo com Triviños (1987), tem por objetivo aprofundar a descrição de determinada realidade. O período de estudo foi de agosto de 2009 a março 2010. Para a coleta dos dados, foram utilizados questionário semi-estruturado, roteiro de entrevista e observação-participante. 


\section{RESULTADOS E DISCUSSÃO}

A pesquisa realizada demonstrou que as cooperativas mencionadas desenvolvem estratégias competitivas. Considerando as informações analisadas, as cooperativas de crédito rural pertecentes às cidades de Bom Despacho, Bambuí, Campo Belo e Nanuque e as cooperativas de crédito mútuo localizadas nas cidades de Formiga, Viçosa, Ouro Branco, Campos Gerais, Sabinópolis e Alpinópolis desenvolvem estratégias atuantes para se manterem competitivas no mercado.

De acordo com o gerente geral da cooperativa da cidade de Bom Despacho, as estratégias estão relacionadas, basicamente, no fornecimento de crédito aos seus associados, taxas de juros e tarifas diferenciadas, qualidade de vida para os cooperados e investimento em tecnologia, de maneira a promover o desenvolvimento regional. Conforme a entrevista, pode-se perceber pelo relato do gerente geral:

\footnotetext{
Entende-se que praticando taxas de juros e tarifas inferiores ao mercado, proporciona aos nossos cooperados uma melhor qualidade de vida. Registra-se ainda que, com recursos oriundos das sobras dimensiona-se recursos financeiros para custear estudos de cooperados e seus familiares. Prioriza também investimentos em tecnologia da informação, capacitação de dirigentes, acompanhamento constante da evolução do mercado financeiro e preocupação com o desenvolvimento regional. (2009).
}

A cooperativa da cidade de Bambuí atua no mercado por meio de taxas diferenciadas, incentivos na formação de programas educacionais, e bom atendimento, enfatizando atenção especial aos associados. Afirma o gerente geral da cooperativa de Bambuí: "A instituição procura sempre estar participando de eventos e programações que possam trazer quaisquer benefícios para a sociedade e principalmente para os nossos associados." (2009).

As estratégias organizacionais da cooperativa de Campo Belo estão direcionadas ao atendimento diferenciado, destacando a conscientização ambiental, menores taxas de juros, como também, visam estimular o crescimento. Afirma o diretor presidente da cooperativa de Campo Belo: "A instituição influencia na vida social de seus cooperados especialmente procurando aprimorar e valorizar o espírito de cooperação, e de seus benefícios para todos." (2009).

A cooperativa da cidade de Nanuque atua em excelência no atendimento, aquisição do crédito dirigido aos associados, menores taxas de juros do mercado de atuação e política de cooperação. O gerente geral da cooperativa explica: "O desenvolvimento sócio-econômico e ambiental é de supra importância para o crescimento e desenvolvimento da cooperativa, pois todo desenvolvimento deve ser sustenta- do na preservação." (2009).

O Quadro 1 resume as principais estratégias adotadas pelas cooperativas de crédito rural estudadas, visando a competitividade no mercado. 
Quadro 1 - Estratégias competitivas adotadas pelas cooperativas de crédito rural estudadas

\begin{tabular}{|c|c|}
\hline Instituições & Estratégias competitivas \\
\hline $\begin{array}{l}\text { Cooperativa Bom } \\
\text { Despacho }\end{array}$ & $\begin{array}{l}\text { - Atenção às modificações do mercado para atender, de forma precisa, às } \\
\text { necessidades dos cooperados; } \\
\text { - Incentivos na formação de programas educacionais; } \\
\text { - Taxas de juros de empréstimos e de cheque especial mais baixas; } \\
\text { - Conscientização dos colaboradores da importância da preservação ambiental; } \\
\text { - Estimular o crescimento sócio-econômico de seus associados. }\end{array}$ \\
\hline $\begin{array}{l}\text { Cooperativa } \\
\text { Bambuí }\end{array}$ & $\begin{array}{l}\text { - Tratamento personalizado e agilidade em todos os processos; } \\
\text { - Taxas de juros menores; } \\
\text { - Incentivos na formação de programas educacionais; } \\
\text { - Fornecer crédito de qualidade e com consciência social; } \\
\text { - Incentivo ao desenvolvimento social, econômico e ambiental. }\end{array}$ \\
\hline $\begin{array}{l}\text { Cooperativa } \\
\text { Campo Belo }\end{array}$ & $\begin{array}{l}\text { - Reconhecimento empresarial, por meio de uma política bem estruturada; } \\
\text { - Presença territorial com filiais em todo o centro-nordeste mineiro; } \\
\text { - Participação ativa nas comunidades e órgãos de ação comunitária; } \\
\text { - Prestação de serviços tipicamente bancários com tecnologia alinhada; } \\
\text {-Incentivos a projetos de reflorestamento e conscientização, partindo do } \\
\text { atendimento. }\end{array}$ \\
\hline $\begin{array}{l}\text { Cooperativa } \\
\text { Nanuque }\end{array}$ & $\begin{array}{l}\text { - Treinamentos, cursos e palestras para os funcionários; } \\
\text { - Bolsa para os colaboradores poderem ingressar na faculdade; } \\
\text { - Ampliação do quadro de associados; } \\
\text { - Menores taxas de juros e promovem desenvolvimentos sócio-econômico e } \\
\text { ambiental }\end{array}$ \\
\hline
\end{tabular}

Fonte: Dados da pesquisa, 2009.

As estratégias pesquisadas identificaram que a cooperativa de crédito mútuo da cidade de Formiga busca soluções financeiras tendo como foco a redução das taxas de serviços, desenvolvem serviços de apoio aos cooperados, atendimento de forma corpórea, reuniões diárias, aprovando liberação de crédito e estrutura organizacional bem definida. Afirma a secretária executiva da cooperativa: "A nossa cooperativa está sempre procurando atender as necessidades dos cooperados de maneira satisfatória, buscando por meio desse o desenvolvimento sócio-econômico e ambiental" (2009).

O Quadro 2 resume as principais estratégias adotadas pelas cooperativas de crédito mútuo estudadas.

Quadro 2 - Estratégias competitivas adotadas pelas cooperativas de crédito mútuo estudadas

\begin{tabular}{|l|l|}
\hline Instituições & Estratégias Competitivas \\
\hline & $\begin{array}{l}\text { - Gestão profissional eficiente; } \\
\text { - Geração de benefícios aos cooperados; } \\
\text { - Capacitação dos colaboradores; }\end{array}$ \\
$\begin{array}{ll}\text { Cooperativa } \\
\text { Formiga }\end{array}$ & $\begin{array}{l}\text { - Estratégias agressivas nas busca de novos clientes; } \\
\text { - Acompanhamentos diários de concorrentes. }\end{array}$ \\
& \\
\hline
\end{tabular}




\begin{tabular}{|c|c|}
\hline $\begin{array}{l}\text { Cooperativa } \\
\text { Formiga }\end{array}$ & $\begin{array}{l}\text { - Estratégias visando soluções financeiras; } \\
\text { - Serviços de apoio aos negócios dos cooperados; } \\
\text { - Atendimento de forma corpórea; } \\
\text { - Agilidade na liberação de crédito; } \\
\text { - Estrutura organizacional bem definida. }\end{array}$ \\
\hline $\begin{array}{l}\text { Cooperativa } \\
\text { Viçosa }\end{array}$ & $\begin{array}{l}\text { - Investimentos em tecnologia da informação; } \\
\text { - Capacitação de dirigentes e quadro de colaboradores; } \\
\text { - Acompanhamento constante da evolução do mercado financeiro; } \\
\text { - Taxa de juros e tarifas inferiores ao mercado. }\end{array}$ \\
\hline $\begin{array}{l}\text { Cooperativa } \\
\text { Ouro } \\
\text { Branco }\end{array}$ & $\begin{array}{l}\text { - Atendimento diferenciado } \\
\text { - Mantendo taxas diferenciadas; } \\
\text { - Incentivos na formação de programas educacionais; } \\
\text { - Estimulam os desenvolvimentos sócio- econômico e ambiental. }\end{array}$ \\
\hline $\begin{array}{l}\text { Cooperativa } \\
\text { Campos } \\
\text { Gerais }\end{array}$ & $\begin{array}{l}\text { - Atenção às mudanças do mercado; } \\
\text { - Atendimento diferenciado; } \\
\text { - Menores taxas de juros; } \\
\text { - Estimular o crescimento sócio- econômico e ambiental. }\end{array}$ \\
\hline $\begin{array}{l}\text { Cooperativa } \\
\text { Alpinópolis }\end{array}$ & $\begin{array}{l}\text { - Excelência em atendimento; } \\
\text { - Atendimento diferenciado; } \\
\text { - Menores taxas de juros; } \\
\text { - Estimular o crescimento sócio-econômico e ambiental. }\end{array}$ \\
\hline $\begin{array}{l}\text { Cooperativa } \\
\text { Sabinópolis }\end{array}$ & $\begin{array}{l}\text { - Treinamento de colaboradores; } \\
\text { - Estabelecimento de parcerias; } \\
\text { - Conscientização ambiental, partindo do atendimento; } \\
\text { - Prestação de serviços bancários com menores taxas; } \\
\text {-Capacitação de profissionais com política de recursos humanos bem estruturada. }\end{array}$ \\
\hline
\end{tabular}

Fonte: Dados da pesquisa, 2009.

Já a outra cooperativa de crédito mútuo da cidade de Formiga desenvolve estratégias a partir do treinamento de seus colaboradores, com foco em ação ética, estabelecimento de parcerias, conscientização ambiental (partindo do atendimento), prestação de serviços bancários com menores taxas e capacitação de profissionais com política de recursos humanos bem estruturada. Afirma o gerente da instituição: "Estamos sempre buscando a plena satisfação de nossos associados e colaboradores, como também o aprimoramento de nossos serviços à fim do desenvolvimento, com foco na sustentabilidade." (2009).

De acordo com o assistente administrativo da cooperativa da cidade de Viçosa as estratégias estão relacionadas com uma maior atenção às modificações do mercado para atender de forma precisa, às necessidades dos cooperados, incentivos na formação de programas educacionais, menores taxas de juros de empréstimos e de cheque especial e conscientização dos colaboradores da importância da preservação ambiental. De acordo com a entrevista, pode-se perceber:

A instituição atua na vida social dos cooperados através de parcerias com os comerciantes locais como, por exemplo, supermercados, lojas de materiais de construção, lojas de eletrodomésticos e etc. Proporcionando aos associados um maior poder de compra, negociando dívidas com outras instituições financeiras. Enfim, a cooperativa faz com que os associados sejam cidadãos ativos na comunidade. (2009). 
A cooperativa da cidade de Ouro Branco adota como estratégia de gestão profissional eficiente, geração de benefícios aos cooperados, capacitação dos colaboradores, procuram manter documentos atualizados para comprovação de cadastro e acompanhamentos diários de concorrentes. Afirma o gerente geral cooperativa: "A nossa prioridade é o comprometimento com nossos associados, buscando novas formas que visam o bem-estar dos funcionários, colaboradores e cooperados, assim como, o desenvolvimento regional."(2009).

As estratégias adotadas pela cooperativa da cidade de Campos Gerais é feita mediante tratamento personalizado e agilidade em todos os processos, taxas de juros menores, incentivos na formação de programas educacionais, fornecimento de crédito de qualidade e com consciência social e incentivo aos desenvolvimentos social, econômico e ambiental. Afirma o gerente da cooperativa: "Procuramos de uma forma objetiva fornecer crédito de qualidade e com consciência social e ambiental, não estamos interessados em apenas fornecer o produto, queremos a melhor opção para nossos sócios. "(2009).

A estratégia competitiva da instituição da cidade de Sabinópolis é feita por meio do reconhecimento empresarial, relacionando uma política bem estruturada, presença territorial com filiais em todo o centro-nordeste mineiro, participação ativa nas comunidades e órgãos de ação comunitária, prestação de serviços tipicamente bancários, com tecnologia alinhada, incentivos a projetos de reflorestamento e conscientização ambiental. Afirma o superintendente de desenvolvimento da cooperativa:

\footnotetext{
A instituição influencia na vida social de seus cooperados por meio de relações de negócios de crédito com os cooperados no fomento de desenvolvimento regional. Além disso, buscam-se ações para um balanço social, relacionadas com o assistencialismo, educação, e meio ambiente. (2009).
}

De acordo com o assessor, em gestão, de negócios da cooperativa da cidade de Alpinópolis, a instituição atua, basicamente, fornecendo bolsa para os colaboradores ingressarem na faculdade, procuram ampliar o quadro de associados, menores taxas de juros e promovem os desenvolvimentos sócio-econômico e ambiental. Segundo a entrevista, percebe-se que:

Viabilizar curso/treinamentos na gestão de negócios, apoia eventos (feiras, exposição, reuniões) ligados à atividade dos associados, acompanha a correta destinação do crédito e concede ou mesmo cria linhas de crédito adaptadas às atividades dos associados. (2009).

De acordo com a pesquisa, foram analisadas a escolaridade dos entrevistados e a relação de sua formação acadêmica com o desenvolvimento da instituição. De acordo com os dados, 53,3\% dos entrevistados possuem curso superior completo, ou seja, são dotados de um conhecimento específico e estratégico, possibilitando um melhor aprimoramento de ideias sendo gerente geral, diretores e superintendente de desenvolvimento. Já 43,7\% dos entrevistados possuem curso de pós-graduação, sendo os responsáveis pela estabilidade das instituições, sendo o presidente e alguns assistentes administrativos. Assim como também há aqueles que representam o nível operacional da cooperativa, são eles os executores das idéias que irão favorecer o desenvolvimento da mesma, conforme ilustrado no 
GRAF. 1, os secretários gerais, secretários executivos e os recepcionistas, representando 1\% da análise da pesquisa.

GRÁFICO 1- Relação da escolaridade dos entrevistados.

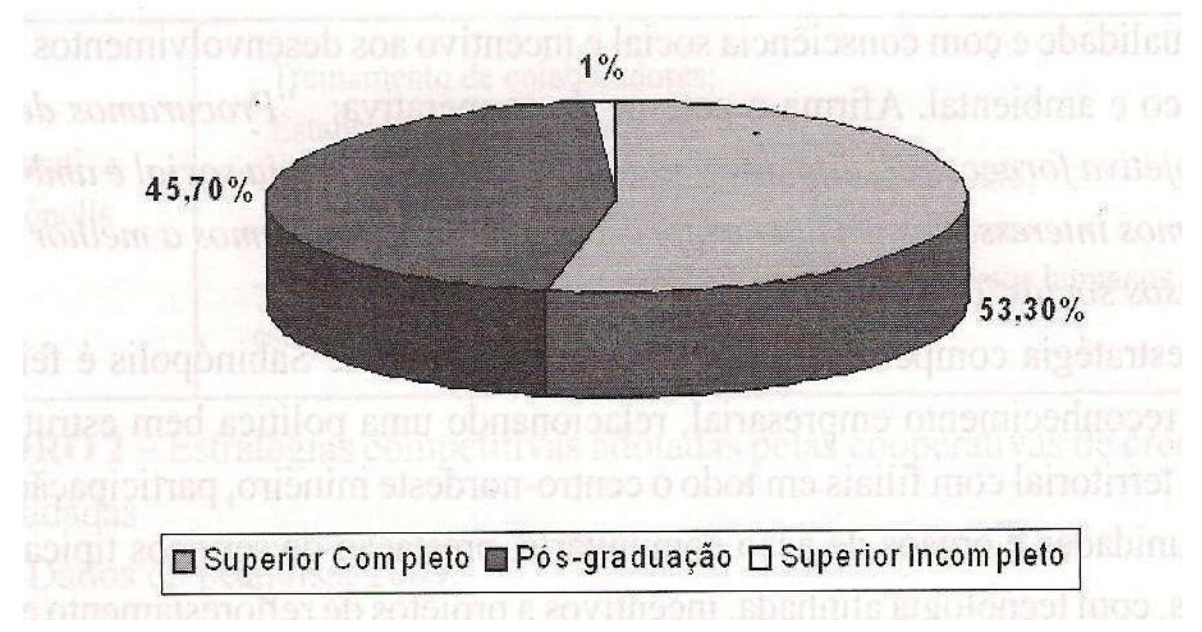

Fonte: Dados da pesquisa, 2009.

De acordo com a pesquisa, a cooperativa da cidade de Bom Despacho atua no mercado com uma taxa de $(2,75 \%)$, proporcionando uma melhor qualidade de vida aos associados e melhorando a relação funcionário-cooperado. A cooperativa da cidade de Bambuí atua no mercado com uma taxa de (3,5\%) possibilitando aos seus associados, um atendimento diferenciando, adaptado às mudanças do mercado.

Em se tratando da cooperativa da cidade de Campo Belo, esta atua com uma taxa diferenciada, de (3\%), valorizando o espírito de cooperação e seus benefícios para todos. Já a cooperativa da cidade de Nanuque atua com excelência em atendimento, crédito dirigido e assistido, com as menores taxas do mercado de atuação $(3,75 \%)$, praticando a política de cooperação e a conscientização, partindo do atendimento. A cooperativa da cidade de Formiga por ser uma instituição sem fins lucrativos, princípios do cooperativismo, emprega taxas de juros menores em torno de (1\%). O objetivo da respectiva instituição é a busca de soluções financeiras, visando apoiar o associado em seus negócios.

De acordo com a cooperativa de crédito mútuo localizada na cidade de Formiga, apresenta uma taxa de $(2,1 \%)$, além de treinamento de seus colaboradores, favorecendo, assim, um melhor conhecimento das necessidades de seus associados. Em se tratando da cooperativa da cidade de Viçosa, a instituição possui uma taxa de (2,5\%), e adota uma gestão profissional eficiente, como também estratégias agressivas na busca de novos clientes, mantendo documentos atualizados para comprovação de cadastro e acompanhamento diário de concorrentes.

A cooperativa da cidade de Ouro Branco atua com incentivos na formação de programas educacionais e taxas de juros de empréstimos e de cheque especial mais baixas (3,5\%). A cooperativa de Campos Gerais atua no mercado com tratamento personalizado e agilidade em todos os processos, taxas de juros menores (2\%), incentivos na formação de programas educacionais e incentivos aos desenvolvimen- tos social, econômico e ambiental. 
Já a cooperativa da cidade de Sabinópolis oferece aos cooperados, crédito a taxas satisfatórias a partir de (1,98\%), tendo como preocupação central o bem-estar dos associados, o desenvolvimento regional, e a prestação de serviços bancários com tecnologia alinhada, como também incentivos aos desenvolvimentos sócio-econômico e ambiental. Já a cooperativa de Alpinópolis oferece taxas diferenciadas, em torno de (1,39\%), favorecendo inúmeros benefícios e satisfação dos associados, em função de uma estrutura mais enxuta, qualificação profissional, como também o desenvolvimento regional. Para se manterem competitivas, as cooperativas trabalham com taxas diferenciadas, o que é ilustrado pelo GRAF., que descreve as taxas de juros aplicadas pelas cooperativas estudadas comparadas com os bancos priva- dos. As taxas de juros das respectivas instituições estudadas são menores que as do bancos privados, apresentando uma variação de $9,5 \%$.

GRÁFICO 2- Comparação da taxa de juros.

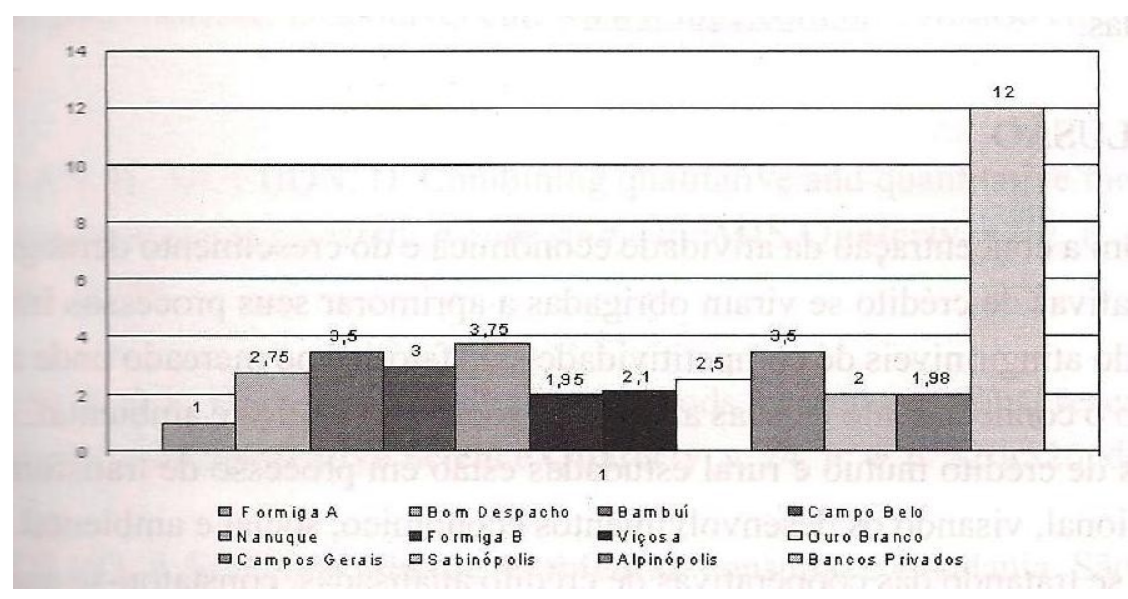

Fonte: Dados da pesquisa, 2009.

Todas as cooperativas mencionadas atuam no mercado com taxas inferiores, atendendo, de forma conjunta, às necessidades de seus associados favorecendo uma melhor qualidade de vida, facilidade ao crédito, reconhecimento empresarial, taxas justas e satisfatórias, maior disponibilidade em recursos (com taxas mais acessíveis), estabelecimento de parcerias, treinamento de colaboradores, atenção às mudanças do mercado, estratégias visando soluções financeiras, como os desenvolvimentos sócioeconômico e ambiental.

As taxas de juros das respectivas cooperativas são menores, se comparadas com as taxas dos bancos privados, que giram em torno de (12\%), facilitando as relações de negócios de crédito para os cooperados, renumeração de aplicações para a empresa, acompanhamento do mercado, tendências e adaptações ao ambiente sócio-econômico e ambiental, favorecendo, assim, um melhor aprimoramento do bem- estar social dos cooperados e funcionários.

As cooperativas mencionadas possuem estratégias competitivas para atuarem no mercado, além de uma preocupação social, econômica e ambiental, principalmente por parte dos associados e cooperados das instituição. Além disso, buscam ações para um balanço social, ações essas relacionadas com o 
assistencialismo, educação, meio ambiente e desportos. A influência na vida social e econômica dos cooperados ocorre de maneira a fomentar o comércio local, por meio das taxas de juros diferenciadas, comparando com as taxas dos bancos privados, facilidade ao crédito, formas de renumeração de aplicações com taxas justas, prestação de serviços bancários com qualidade e baixo custo.

Uma outra forma mencionada foi a melhoria da autoestima dos associados, como também o bom relacionamento funcionário-cooperado e a conscientização ambiental, partindo do atendimento. As cooperativas de crédito mútuo e rural estão contribuindo para geração de renda, emprego e o foco no desenvolvimento sustentável, por meio das práticas do cooperativismo e de estratégias organizacionais bem estruturadas.

\section{CONCLUSÃO}

Com a concentração da atividade econômica e do crescimento demográfico, as cooperativas de crédito se viram obrigadas a aprimorar seus processos internos, objetivando atingir níveis de competitividade satisfatórios no mercado onde atuam, bem como o conhecimento de suas atividades sócio-econômica e ambiental. As cooperativas de crédito mútuo e rural estudadas estão em processo de transformação organizacional, visando os desenvolvimentos econômico, social e ambiental.

Em se tratando das cooperativas de crédito analisadas, constatou-se que estas instituições financeiras trabalham com dinamismo e estratégias competitivas, por meio do acompanhamento do ambiente externo, tendências e adaptação ao meio, menores taxas de juros, conscientização ambiental, partindo do atendimento, e de campanhas ambientais, formação de programas educacionais, excelência em atendimento e ampliação do quadro de colaboradores, com intuito de promover os desenvolvimentos sócio-econômico e ambiental.

Deste modo, as cooperativas de crédito rural de Bom Despacho, Bambuí, Campo Belo e Nanuque atuam na formação de programas educacionais, conscientização ambiental, e menores taxas de juros. As cooperativas de crédito mútuo situadas nas cidades de Formiga, Viçosa, Ouro Branco, Campos Gerais, Sabinópolis e Alpinópolis têm cumprido o seu papel, priorizando ações associativas, visando o desenvolvimento regional, a formação de programas educacionais, menores taxas de serviços e o aprimoramento de serviços, por meio da capacitação dos clientes internos e associados. Tanto as cooperativas de crédito rural quanto as cooperativas de crédito mútuo visam os desenvolvimentos social, econômico e ambiental na região de atuação.

\section{REFERÊNCIAS}

ASSEMBLÉIA LEGISLATIVA DE MINAS GERAIS (ALMG). Municípios mineiros. Disponível em: < www.almg.gov.br>. Acesso em: 23 mar. 2010. 
COTÈ, D.; VÉZIMA, M. L'éducation coopérative: outil essentiel á la gestion coopérative, conférence dans le cadre de I'ACFAS. [S.l.: s.n.], 1994.

GIL, A . C. Métodos e técnicas de pesquisa social. São Paulo: Atlas, 1999.

INSTITUTO BRASILEIRO DE GEOGRAFIA E ESTATÍSTISCA (IBGE). Cidades. Região Sudeste. Disponível em: <www.ibge.com.br>. Acesso em: 16 mar. 2010.

KAPLAN, B.; DUCHON, D. Combining qualitative and quantitative methods in information systems research: a case study. In: MIS Quaterly, USA, v. 12, n. 4, p. 571- 586, Dec. 1988.

MAANEN, J. V. Reclaiming qualitative methods for organizational research: a preface. In: Administrative science quaterly, USA, v. 24, n. 4, p. 520-526, Dec. 1979.

PORTILHO, F. Sustentabilidade ambiental: consumo e cidadania. São Paulo: Cortez, 2005.

SCHARDONG, A. Cooperativa de crédito: instrumento de organização econômica da sociedade. Porto Alegre: Rigel, 2003.

SMIRCH, L.; STURBART, C. Strategic management in a enacted world. In: Academy of management journal, USA, v. 10, n. 4, p. 724-736, 1985.

SOUZA, E. G. V. Cooperativismo de crédito no Brasil. Curitiba: Juruá, 2008.

TRIVIÑOS, A. N. S. Introdução à pesquisa em ciências sociais: a pesquisa qualitativa em educação. São Paulo: Atlas, 1987.

YIN, R. K. Estudo de caso: planejamento e métodos. 2. ed. Porto Alegre: Bookman, 2001. 